\title{
Orientation of fish larvae in situ is consistent among locations, years and methods, but varies with time of day
}

\author{
Jeffrey M. Leis ${ }^{1,2, *}$, Claire B. Paris ${ }^{3}$, Jean-Olivier Irisson ${ }^{3,5,6}$, Michelle N. Yerman ${ }^{1,7}$, \\ Ulrike E. Siebeck ${ }^{4}$ \\ ${ }^{1}$ Ichthyology, Australian Museum, Sydney, New South Wales 2010, Australia \\ ${ }^{2}$ Institute for Marine and Antarctic Studies, University of Tasmania, Tasmania 7000, Australia \\ ${ }^{3}$ Division of Applied Marine Physics, Rosenstiel School of Marine and Atmospheric Sciences, University of Miami, Miami, \\ Florida 33149-1098, USA \\ ${ }^{4}$ School of Biomedical Sciences, The University of Queensland, St. Lucia, Queensland 4072, Australia \\ ${ }^{5}$ Present address: UPMC Univ Paris 06, LOV, Observatoire Oceanologiqué, 06234, Villefranche-sur-Mer, France \\ ${ }^{6}$ Present address: CNRS, UMR 7093, LOV, Observatoire Océanologique, 06234, Villefranche-sur-Mer, France \\ ${ }^{7}$ Present address: West Australian Fisheries, Perth, Western Australia 6850, Australia
}

\begin{abstract}
Understanding larval dispersal requires knowledge of whether larvae in situ have orientated swimming, and how this varies temporally and spatially. Orientation of $>300$ settlementstage larvae of Chromis atripectoralis (Pomacentridae) measured over 1998-2008 by divers near Lizard Island, Great Barrier Reef was consistent. All 10 data sets had southerly orientation at all locations; $94 \%$ of larvae swam directionally. Median bearings east and west of Lizard Island were $166^{\circ}$ and $170^{\circ}$, respectively. Orientation precision was significantly higher under sunny than cloudy skies. Similar mean bearings were obtained in 2008 with more than 125 larvae observed in a drifting in situ chamber (DISC). Orientation varied with time of day. In sunny conditions, precision was weakly, significantly correlated with time of day, but not solar elevation; however, a greater proportion of larvae was significantly directional at low $\left(<50^{\circ}\right)$ than at high $\left(>50^{\circ}\right)$ solar elevation. Mean bearing and time of day were weakly, but significantly correlated. Bearings changed from SE during most of the day to SSW in the late afternoon, with distribution of bearings significantly different. Location-independent but diurnally-dependent orientation implies that larvae used celestial cues for orientation. Of 91 Pomacentrus lepidogenys larvae that were followed by divers, $89 \%$ swam directionally, but orientation differed among locations and years. DISC results with 20 larvae were similar. The similarity of orientation returned by different methods used on 2 fish species corroborates previous results using diver following. Both methods are useful for the study of larval-fish orientation in situ: each has advantages and limitations, and their use is complementary.
\end{abstract}

KEY WORDS: Pomacentridae $\cdot$ Reef-fish $\cdot$ Orientation $\cdot$ Larva $\cdot$ Solar $\cdot$ Celestial $\cdot$ Visual cue Dispersal $\cdot$ Connectivity

\section{INTRODUCTION}

It has become increasingly obvious that larvae of many marine fishes have behavioural abilities sufficient to influence dispersal outcomes. The capacity of larvae of many species to swim at high speeds for long periods for much of their pelagic larval duration (PLD) is well documented (Fisher \& Leis 2009, Leis 2010). Yet, regardless of swimming speeds or durations, unless larvae can swim in an orientated manner, behaviour will have limited direct influence on dispersal. Therefore, to understand and model larval 
dispersal, researchers need to learn more about orientation abilities in fish larvae, and the cues used for orientation (North et al. 2009, Leis et al. 2011, Staaterman \& Paris 2013).

Little is known of how orientation behaviour of larval fishes in situ might vary spatially and temporally. Both location-dependent and location-independent orientation have been reported (Stobutzki \& Bellwood 1998, Leis \& Carson-Ewart 2003, Leis et al. 2006, 2007, 2009, Paris et al. 2013). In terms of temporal variation, attention has focused on ontogeny of orientation behaviour, showing that orientation varies ontogenetically in some species (Leis 2010). A few studies have examined changes in larval-fish orientation with time of day in tanks (Mouritsen et al. 2013) or in situ (Leis \& Carson-Ewart 2003), but we are unaware of any studies that have studied variation in larval-fish orientation over longer time scales.

Evidence exists that larval fishes may use celestial cues for orientation (Waterman 1988, Leis \& CarsonEwart 2003, Mouritsen et al. 2013, Berenshtein et al. 2014), as is the case for many invertebrates and birds (Gould \& Gould 2012). If celestial cues are indeed used for orientation by fish larvae, then several expectations follow including (1) orientation should be location-independent, (2) orientation precision and bearing should vary during the day, and (3) orientation should be poorer when the sky is obscured by heavy cloud cover because clouds can not only obscure a direct view of the sky and sun, but also alter the skylight polarization (Pomozi et al. 2001, Hegedüs et al. 2007). Herein, we test some of these expectations.

Orientation of larval fishes is difficult to study in situ. Until recently, the only practical way to study orientation behaviour of fish larvae in the ocean was for scuba divers to follow the larvae and to directly measure swimming direction with a hand-held compass (Leis et al. 1996). This approach, which we refer to as Following, has revealed that larvae of most studied species swim in a highly orientated manner in the ocean (Leis et al. 1996, 2009, Trnski 2002, Hindell et al. 2003, Leis \& Carson-Ewart 2003). Circumstantial evidence has supported the validity of orientation data collected in this way (Leis et al. 1996, Leis \& Carson-Ewart 1998). Yet, questions remain about the influence that the relatively large divers might have on behaviour of the larvae. Further, Following necessarily has limitations in terms of duration, depth of observations, and time of day.

A new methodology to study orientation of larvae in situ allows examination of some of these issues. It consists of a drifting, subsurface arena wherein behaviour of larvae can be imaged for later analysis
(Paris et al. 2008, Irisson et al. 2009). The original hardware has been developed and refined, largely using clear acrylic in its construction, substituting a digital still camera for the video camera, reversing the camera to look upward, and adding sensors. With these changes, the new apparatus was renamed DISC (drifting in-situ chamber; see Paris et al. 2013). The DISC opens several lines of research that are not practical or possible with Following, including longer-term observations, observations at night or at depths greater than $20 \mathrm{~m}$, and the manipulation of sensory cues. However, the data available from this new approach are as yet limited, and there has been no attempt to compare this new methodology to Following. Furthermore, a larva in a relatively small observation arena might not orientate in the same way as one free to swim in the pelagic water column.

Our purpose here is to address some of these issues with a unique and extensive in situ data set from the Lizard Island region of the Great Barrier Reef. First, we examine how orientation of settlement-stage larvae of 2 pomacentrid damselfish species varied over $10 \mathrm{yr}$, and among locations near Lizard Island. We address spatial variation with regard to distance from the reef (100-1000 m) and in areas about $4 \mathrm{~km}$ apart east and west of Lizard Island. Second, we examine how orientation in one of these species varies at different times during daylight hours, which allowed us to test whether the patterns of orientation are consistent with the use of celestial cues. Finally, we compare 2 methods for studying orientation of larval fishes in the sea: Following and the DISC.

\section{MATERIALS AND METHODS}

\section{Study location}

Orientation of larvae was studied 100-1000 m off the fringing reef edge in 2 locations near Lizard Island, Great Barrier Reef (14 ${ }^{\circ} 40^{\prime} \mathrm{S}, 145^{\circ} 27^{\prime} \mathrm{E}$; Fig. 1): off the east (windward) side, and B) off the west (leeward) side. Details of these 2 locations are available in Leis \& Carson-Ewart (2003) and Leis (2004). All observations considered here were made from November to February (i.e. late Austral spring and summer).

\section{Study species}

Size at settlement, and hence size of larvae studied here, is 7-10 $\mathrm{mm}$ standard length for Chromis atripectoralis and 11-13 $\mathrm{mm}$ for Pomacentrus lepi- 


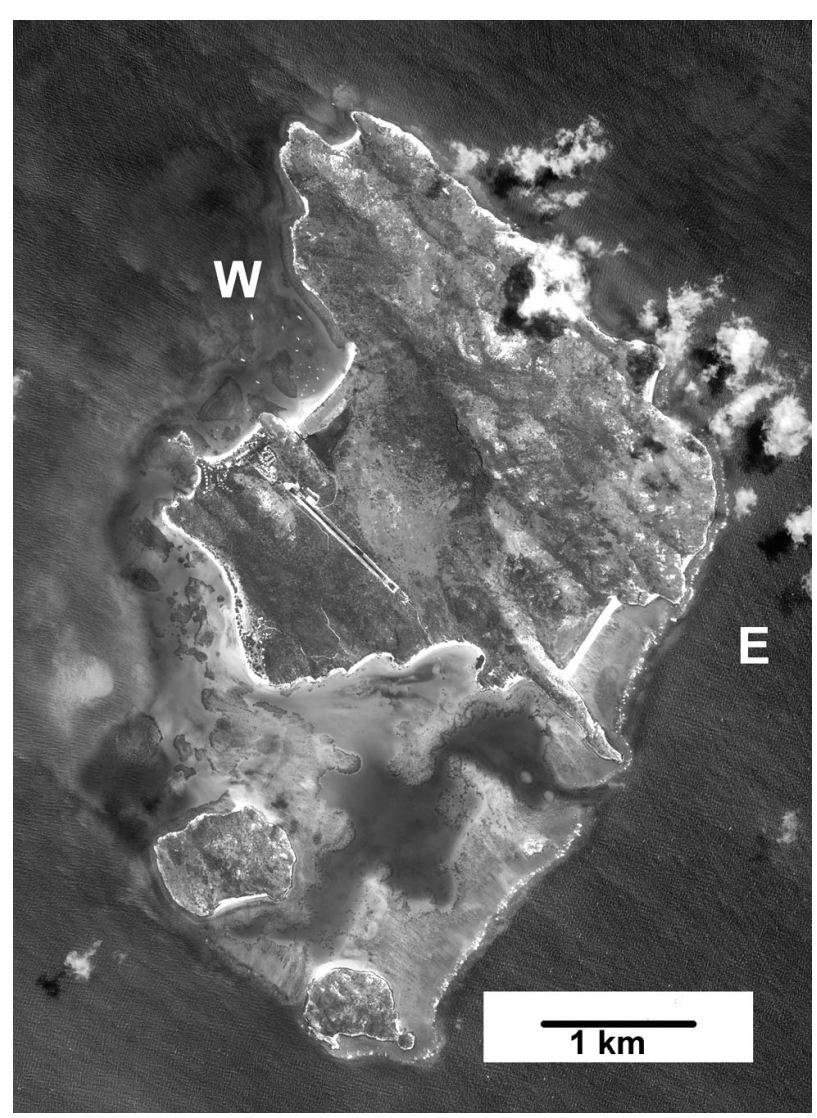

Fig. 1. Lizard Island, Great Barrier Reef, Australia. The study areas off the east and west sides of the island are indicated by $\mathrm{E}$ and $\mathrm{W}$, respectively. North is toward the top of the figure. Satellite image ${ }^{\circledR}$ GeoEye 2005, used with permission

dogenys. Both have a PLD of about 2-3 wk (Wellington \& Victor 1989, Bay et al. 2006). Larvae were captured in light traps 50 to $100 \mathrm{~m}$ seaward of the reef edge, and observed in situ on the day of capture. Between capture and in situ observation, the larvae were kept in covered 151 buckets, with frequent changes of sea water.

\section{Following by divers}

The methodology of Following is described in previous publications (especially Leis et al. 1996, Leis \& Carson-Ewart 1997, 1998). Briefly, larvae were released $5 \mathrm{~m}$ below the surface, usually one at a time, by a pair of SCUBA divers who followed them at 1-2 $\mathrm{m}$ distance, and who recorded depth (with $0.1 \mathrm{~m}$ precision) and orientation (degrees magnetic to nearest $5^{\circ}$ ) at $30 \mathrm{~s}$ intervals. Observation runs typically lasted 10 minutes, providing 21 measures of swimming direction. Within-run statistics refer to these 21 observations. Among-run statistics refer to the distribution of mean bearings of individual runs. Bearings are reported as degrees magnetic, which in the study area differs from degrees true by $7^{\circ}$.

\section{Temporal and spatial variation}

To examine temporal and spatial variation in orientation, 6 sets of Following data for C. atripectoralis, and 2 for $P$. lepidogenys were available from previous studies at Lizard Island (Leis et al. 2002, Leis \& Carson-Ewart 2003; see Table 1). During the present study, we obtained 4 Following data sets for $C$. atripectoralis: one each from west and east of Lizard Island in January-February 2008, and 2 from west of the island in November-December 2008 (one of which involved the release of 10-12 larvae at a time). We obtained one Following data set for P. lepidogenys from west of the island in November-December 2008. The influence of distance from the reef edge $(100,500$ and $1000 \mathrm{~m}$ ) on orientation was assessed by Leis \& Carson-Ewart (2003), and we report their assessment.

\section{Diurnal variation}

In order to examine variation in orientation during the day (hereafter, diurnal analysis), we utilized a reduced data set to avoid the possibility of confounding the diurnal analysis with influences involving different locations or experimental manipulations. Therefore, we included only data from west of Lizard Island, the location where we had the most data and the broadest coverage of times (see Table 1). We also excluded 2 data sets (CFW3 and 4; see Table 1) obtained when reef sounds were being broadcast (Leis et al. 2002) and a data set (CFW7) obtained when groups of larvae were being followed (J.-O. Irisson et al. unpubl.), as in both cases, orientation of the larvae had significantly different variability from that without the manipulations. An additional Following data set for $C$. atripectoralis was gathered in November-December 2011 from west of the island. These data were taken between 11:45 and 15:40 h local time (mean 13:10 h: all times are the start time of the run) to obtain information at times that were poorly represented in the other data sets. This provided 154 Following releases taken from 19 Nov to 22 Feb at starting times ranging from 08:36 to 18:02 h. For some analyses, these data were divided into $5 \times 2 \mathrm{~h}$ bins, starting from 08:30 $h$, resulting in $\mathrm{n}=24,45,33,35$ and 17 , respectively. Of these, 114 were obtained in sunny 
conditions (including scattered 'trade-wind clouds'), and 29 under full cloud cover. The field notes did not specify whether it was cloudy or sunny for 11 releases, so these were used only for analyses including all data. Insufficient diurnal coverage of $P$. lepidogenys data was obtained for diurnal analysis.

\section{DISC}

The DISC equipment and methodology are described by Paris et al. $(2008,2013)$ and Irisson et al. (2009). The DISC is a Lagrangian drifter with a circular, behavioural chamber with an upward looking camera positioned to capture time-lapse images of a larva placed within the chamber. A thin line links the DISC's primarily clear acrylic structure to a surface float, and a drogue underneath keeps it locked in the currents. A compass and sensors attached to the DISC's frame record environmental variables experienced by the fish larva in the chamber. The chamber is transparent to visible light, odour and sound but can be changed for cue manipulation.

In this study, a larva was inserted into the mesh chamber (40 $\mathrm{cm}$ diameter, $10 \mathrm{~cm}$ high), and the DISC launched to quickly reach the measurement depth. Based on the modal vertical distribution of C. atripectoralis from Following studies (Leis 2004), the DISC was suspended $9 \mathrm{~m}$ below the surface. It then drifted undisturbed, typically for 20 min (5 min of acclimation and 15 min observation), while the behaviour of the larva was captured by images taken every $2 \mathrm{~s}$. The position of the larva in the image was subsequently digitized, and corrected for rotation of the DISC. Larval positions in the DISC were subsampled every $10 \mathrm{~s}$, during which time the larva could easily swim across the chamber, creating an independent subset of 60 positions. 'Within-run' statistics refer to these 60 observations. 'Among-run' statistics refer to the distribution of mean bearings of individual runs. Data handling and analysis are detailed elsewhere (Paris et al. 2008, 2013, Irisson et al. 2009).

For C. atripectoralis, 4 data sets were obtained with the DISC: 3 east, and one west of the island. For $P$. lepidogenys, one DISC data set was obtained from west of the island. All DISC data were gathered in November-December 2008 (see Table 1).

\section{Comparison of methods}

We compared results of DISC and Following by contrasting the distribution of bearings from the
DISC and Following data sets pairwise with appropriate statistical tests. We asked (1) if the differences between data sets involving between-method contrasts (i.e. Following vs. DISC) were different from those involving within-method contrasts, and (2) if within-method contrasts for DISC differed from those for Following. We made similar comparisons involving precision of directionality and orientation.

\section{Data analysis}

Circular statistics were used to analyze directional data (see Zar 1996 for details) and were done largely with Oriana software (Kovach Computing Services), including calculating mean direction, median and $95 \%$ confidence interval (95\% CI) of the median direction, directional precision (length of the mean vector, r), Rayleigh Tests (R test) for single sample tests for uniformity of the distribution of angles, Watson U2 test (WU2) for multiple sample tests for differences in distribution of bearings, and circularcircular correlation (CC). Tests for differences of angular dispersion between samples were done with the 2-sample or multi-sample Walraff Test (W test, following Zar 1996): this was used to test for differences in variability in among-run (second-order) orientation. Tests involving $\mathbf{r}$ (which varies from a low of 0 to a high of 1) used the non-parametric MannWhitney test (MW test) or Kruskall-Wallis test (KW test), and included all runs. In all tests, a p-value < 0.05 was considered significant. No correction for multiple testing was done: rather, we provide actual $\mathrm{p}$-values to allow the reader to assess if a Type I error due to multiple testing was likely.

For each run, the mean bearing was computed and its significance assessed with the R test. Significant runs are said to be directional. Only those significant means were used in among-run (second-order) analyses (using R or WU2 tests) to assess the overall orientation within each dataset and for comparisons between datasets.

In order to compare the observations made by Following and DISC, we were interested in both the direction and precision of orientation at both withinrun and among-run levels. Comparisons of bearings and precision were first made pairwise between all datasets (i.e. individual data sets were compared in all combinations 2 at a time), and analysed in terms of location (East vs. West) and method (DISC vs. Following). Then, data were pooled by location and method into 4 categories (DISC West, DISC East, Following West, Following East), to highlight geograph- 
ical or methodological effects. For C. atripectoralis, this resulted in DISC East ( $\mathrm{n}=3$ data sets), DISC West ( $\mathrm{n}=1)$, Following East $(\mathrm{n}=3)$, and Following West (n = 7). Observations of $P$. lepidogenys were made only west of the island ( 3 Following and 1 DISC data sets). Finally data were pooled by method only, to specifically test Following against DISC. These test results are summarized in the Results, and presented in more detail in the Supplement at www.int-res. com/articles/suppl/m505p193_supp.pdf.

In most cases, we present medians, rather than means, for $\mathbf{r}$ and among-run bearings. For $\mathbf{r}$ this is because the length of the mean vector is constrained between 0 and 1 , so we used non-parametric statistical methods for its analysis. For bearings, nonparametric circular statistical tests were the most appropriate in many cases due to their less restrained assumptions. The median is the most appropriate measure of central tendency when using nonparametric tests. Further, with circular statistics, the $95 \%$ CI of the median provides a more readily understandable measure of error than either circular variance or circular standard deviation, which are not directly equivalent to their non-circular counterparts.

\section{RESULTS}

\section{Orientation patterns over years and locations}

Following by divers

The southerly orientation in 278 runs of Chromis atripectoralis larvae as measured by Following was remarkably consistent (all data-set medians were SE to SSW) over both location and time (Table 1). In the 10 Following data sets, 82 to $100 \%$ (mean 93\%) of larvae had significant within-run directionality, with a median $\mathbf{r}$ range of $0.67-0.95$ (Fig. 2, Table 1). The median bearing of the 10 data sets was to the south, varying between 136 and 206 ${ }^{\circ}$, and among-run orientation was significant ( $p<0.05, R$ test) in 7 data sets. The median bearing of all 10 pooled data sets was $168^{\circ}$, and was significantly directional (Table 1 ). The median bearing of the 3 data sets from east of the island was $166^{\circ}$, and that of the 7 data sets from west the island was $170^{\circ}$ : both were significant (Table 1).

In $C$. atripectoralis, variation in orientation with distance from the reef edge was considered by Leis \& Carson-Ewart (2003), who found no significant difference in mean bearings ranging from $137^{\circ}$ to $176^{\circ}$ between 100, 500 and $1000 \mathrm{~m}$ from the reef east of the island. In the morning on the west side, orienta- tion at all 3 distances from the reef was to the southeast, but orientation $500 \mathrm{~m}$ from the reef was significantly more easterly $\left(105^{\circ}\right)$ than it was either 100 or $1000 \mathrm{~m}$ from the reef (151 and $166^{\circ}$, respectively). However, in the afternoon on the west side, there was no significant difference with distance from the reef edge in mean bearings of $99^{\circ}$ to $210^{\circ}$.

Fewer data were available for Pomacentrus lepidogenys, and only from the west side of the island, but orientation in 91 runs of this species was less consistent over time than that of C. atripectoralis (Table 1, Fig. 3). In the 3 Following data sets, 85.7 to $95.5 \%$ of $P$. lepidogenys larvae had significant within-run directionality, with median $\mathbf{r}$ range of 0.79-0.89. Only 1 of the 3 data sets (PFW2) had significant among-run orientation, and the median bearings ranged widely: $140^{\circ}, 185^{\circ}$ and $346^{\circ}$.

$P$. lepidogenys had significant differences in mean bearing among distances from the reef both morning and afternoon (Leis \& Carson-Ewart 2003). In both morning and afternoon, only the $1000 \mathrm{~m}$ distance had a significant mean bearing. In the morning, mean

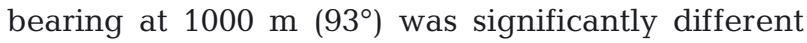
from mean bearings at 100 or $500 \mathrm{~m}\left(200^{\circ}\right.$ and $266^{\circ}$, respectively), whereas the latter 2 did not differ. In the afternoon, the results were similar: $163^{\circ}$ at $1000 \mathrm{~m}, 188^{\circ}$ at $100 \mathrm{~m}$ and $249^{\circ}$ at $500 \mathrm{~m}$, with $1000 \mathrm{~m}$ significantly different from the other two.

\section{DISC}

The 4 DISC data sets of 126 C. atripectoralis runs (Table 1, Fig. 2) provided similar results to the Following data. Between 77 and $97 \%$ (mean 92\%) of larvae had significant within-run directionality, with median $\mathbf{r}$ range of $0.60-0.83$. Three of 4 data sets had southerly median bearings ( 2 were significant; Table 1), whereas the remaining data set (CDW1) had a non-significant north-westerly median bearing $\left(318^{\circ}\right)$. The median bearing for all pooled DISC C. atripectoralis was $173^{\circ}$ and significant (Table 1).

In the single $P$. lepidogenys DISC data set of 20 runs (Table 1, Fig. 3), $95 \%$ of larvae had significant withinrun directionality, but the north-westerly among-run median bearing $\left(334^{\circ}\right)$ was not significant.

\section{Diurnal study: orientation in relation to time of day, solar elevation and sky conditions}

Using the Following method, time-dependent changes in both direction and precision of orientation were 
Table 1. Orientation of larvae of Chromis atripectoralis and Pomacentrus lepidogenys around Lizard Island using 2 techniques. The 4-symbol dataset codes indicate the species (C or P: C. atripectoralis or P. lepidogenys), method (F or D: following by divers, or drifting in situ chamber [DISC] observations), location (E or W: east or west side), and dataset number. Times are at the start of a run. Techniques were consistent, but data were recorded in several studies and conditions. Unless noted otherwise, observations were under ambient conditions, meaning individual larvae observed in an unmodified environment. Modifications include broadcasting of sound near the larvae (reef sound for CFE2 and CFW2, and 'white noise' for CFW4), partial shading of the observed individuals (CDE2), and observation of groups of 10-12 larvae released simultaneously (CFW7). For each dataset we report the proportion of directional larvae (n dir. / total) and the median within-run $\mathbf{r}$ (and its $95 \%$ CI), a measure of precision. Directional bearings were used in an among-run (i.e. second-order) analysis, for which we report the median bearing (with $95 \%$ CI: note that the CIs run in a clockwise direction), the per-dataset $\mathbf{r}$ and the p-value (R test, in bold if significant). In addition, data were pooled and summarized per location (East/West), method (Following/DISC), and species

\begin{tabular}{|c|c|c|c|c|c|c|c|}
\hline \multirow{2}{*}{$\begin{array}{l}\text { Dataset } \\
\text { code }\end{array}$} & \multicolumn{2}{|c|}{ - Data source } & \multicolumn{2}{|c|}{ Within-run } & \multicolumn{2}{|c|}{ Among-run } & \multirow[b]{2}{*}{$\begin{array}{c}\mathrm{R} \text { test } \\
\mathrm{p} \text {-value }\end{array}$} \\
\hline & Date & $\begin{array}{l}\text { Time }(\mathrm{h}), \text { mean } \\
\text { (range) }\end{array}$ & $\begin{array}{c}\text { n dir./ } \\
\text { total }\end{array}$ & $\begin{array}{l}\text { Median } \mathbf{r} \\
{[95 \% \mathrm{CI}]}\end{array}$ & $\begin{array}{c}\text { Median bearing } \\
{[95 \% \mathrm{CI}]}\end{array}$ & $\mathbf{r}$ & \\
\hline CFE1 & Dec 98, Feb $99^{a}$ & $09: 24(08: 23-12: 05)$ & $39 / 40$ & $0.91[0.84-0.95]$ & $143^{\circ}[111-179]$ & 0.48 & $<10^{-4}$ \\
\hline CFE2 & Dec $99^{b}$ & 11:38 (09:23-14:20) & $15 / 17$ & $0.87[0.78-0.96]$ & $160^{\circ}[38-247]$ & 0.13 & 0.79 \\
\hline CFE3 & Jan-Feb $08^{c}$ & $12: 36(09: 52-15: 05)$ & $20 / 20$ & $0.74[0.68-0.86]$ & $203^{\circ}[152-258]$ & 0.41 & 0.03 \\
\hline CFE All & All East & & $74 / 77$ & $0.87[0.80-0.92]$ & $166^{\circ}[150-202]$ & 0.36 & $<10^{-4}$ \\
\hline CFW1 & Dec 98, Feb 99, Jan $00^{a}$ & $10: 43(08: 36-13: 45)$ & $42 / 48$ & $0.83[0.69-0.88]$ & $136^{\circ}[116-166]$ & 0.58 & $<10^{-6}$ \\
\hline CFW2 & Feb 99, Jan $00^{\mathrm{a}}$ & $16: 12(14: 46-18: 02)$ & $41 / 44$ & $0.87[0.45-0.94]$ & $206^{\circ}[170-234]$ & 0.29 & 0.03 \\
\hline CFW3 & Dec $99^{\mathrm{b}}$ & $11: 25(09: 07-13: 40)$ & $19 / 22$ & $0.82[0.45-0.94]$ & $143^{\circ}[81-195]$ & 0.29 & 0.20 \\
\hline CFW4 & Jan $01^{\mathrm{b}}$ & $10: 50(09: 45-13: 26)$ & $23 / 23$ & 0.89 [0.80-0.95] & $177^{\circ}[162-216]$ & 0.64 & $<10^{-4}$ \\
\hline CFW5 & Jan-Feb $08^{c}$ & $12: 18(10: 57-13: 25)$ & $9 / 11$ & $0.76[0.11-0.88]$ & $167^{\circ}[133-197]$ & 0.82 & 0.001 \\
\hline CFW6 & Nov-Dec $08^{\mathrm{c}}$ & $12: 08(09: 54-14: 54)$ & $17 / 18$ & $0.91[0.64-0.96]$ & $172^{\circ}[126-237]$ & 0.28 & 0.26 \\
\hline CFW7 & Nov-Dec $08^{\mathrm{c}}$ & $12: 18(09: 20-15: 21)$ & $35 / 35$ & $0.95[0.92-0.97]$ & $192^{\circ}[158-215]$ & 0.56 & $<10^{-5}$ \\
\hline CFW All & All West & & $186 / 201$ & $0.88[0.84-0.90]$ & $170^{\circ}[162-180]$ & 0.43 & $<10^{-6}$ \\
\hline CF All & All Locations & & $260 / 278$ & $0.87[0.84-0.90]$ & $168^{\circ}[160-176]$ & 0.41 & $<10^{-6}$ \\
\hline CDE1 & Nov-Dec $08^{c}$ & $12: 38(09: 24-15: 11)$ & 33 / 34 & $0.67[0.36-0.88]$ & $164^{\circ}[91-213]$ & 0.09 & 0.78 \\
\hline CDE2 & Nov-Dec $08^{\mathrm{c}}$ & $12: 20(09: 32-15: 42)$ & $23 / 30$ & $0.60[0.20-0.68]$ & $144^{\circ}[125-173]$ & 0.62 & $<10^{-4}$ \\
\hline CDE3 & Nov-Dec $08^{\mathrm{c}}$ & $12: 32(09: 45-15: 19)$ & $32 / 33$ & $0.83[0.68-0.95]$ & $203^{\circ}[171-224]$ & 0.53 & $<10^{-4}$ \\
\hline CDE All & All East & & $88 / 97$ & $0.68[0.58-0.79]$ & $173^{\circ}[160-195]$ & 0.34 & $<10^{-4}$ \\
\hline CDW1 & Nov-Dec $08^{c}$ & $11: 53(09: 10-14: 41)$ & $28 / 29$ & $0.61[0.50-0.80]$ & $318^{\circ}[272-40]$ & 0.08 & 0.83 \\
\hline CD All & All Locations & & $116 / 126$ & $0.67[0.59-0.77]$ & $173^{\circ}[160-196]$ & 0.24 & 0.001 \\
\hline PFW1 & Nov 96, Nov-Dec $99^{a}$ & $10: 50(09: 08-13: 39)$ & $36 / 41$ & $0.79[0.68-0.86]$ & $140^{\circ}[86-200]$ & 0.17 & 0.34 \\
\hline PFW2 & Nov 00, Jan $01^{\mathrm{a}}$ & $16: 01(14: 59-17: 06)$ & $21 / 22$ & $0.84[0.73-0.92]$ & $185^{\circ}[157-240]$ & 0.52 & 0.003 \\
\hline PFW3 & Nov-Dec $08^{c}$ & $13: 12(10: 17-15: 48)$ & $24 / 28$ & $0.89[0.72-0.95]$ & $346^{\circ}[273-59]$ & 0.09 & 0.81 \\
\hline PFW All & All West & & $81 / 91$ & $0.85[0.79-0.88]$ & $200^{\circ}[159-226]$ & 0.17 & 0.10 \\
\hline PDW1 & Nov-Dec $08^{\mathrm{c}}$ & $11: 05(08: 59-15: 49)$ & $19 / 20$ & $0.75[0.54-0.87]$ & $334^{\circ}[275-62]$ & 0.08 & 0.88 \\
\hline
\end{tabular}

found both within runs and among runs in C. atripectoralis. As this study was largely exploratory, we have subdivided and analyzed the data several ways to assess related, but somewhat different possibilities.

\section{Within-run directionality}

A total of 138 of the 154 C. atripectoralis individuals $(89.6 \%)$ in the Diurnal study had significantly directional trajectories ( $\mathrm{R}$ test, $\mathrm{p}<0.05$ ). Under sunny conditions, 105 of 114 individuals (92.1\%) were significantly directional. Under cloudy skies, 24 of 29 individuals $(82.8 \%)$ were significantly directional. The proportion of directional individuals did not differ significantly between sunny and cloudy condi- tions $\left(\chi^{2}, p=0.14\right)$. However, precision of directionality (r) was significantly greater under sunny (median $\mathbf{r}=0.87$ ) than cloudy (median $\mathbf{r}=0.70$ ) conditions (2-tailed, MW test, $\mathrm{p}=0.0011, \mathrm{n}_{\text {sunny }}=114, \mathrm{n}_{\text {cloudy }}=$ 29), which is consistent with use of celestial cues for orientation.

Under sunny skies, within-run precision of directionality increased during the day. Precision (r) and time of day were significantly, although weakly, correlated $\left(\mathbf{r}=0.043 \times\right.$ time $+0.559, \mathrm{R}^{2}=0.043, \mathrm{p}=0.026$, $\mathrm{n}=114$, units of time as proportion of $24 \mathrm{~h}$; Fig. 4). The correlation became non-significant when all data were included $\left(\mathrm{R}^{2}=0.01, \mathrm{p}=0.23, \mathrm{n}=154\right)$. Although median precision was greater in the mid and late afternoon ( $\mathbf{r}=0.88,0.93$, respectively) than for mid-morning, late morning and early afternoon 

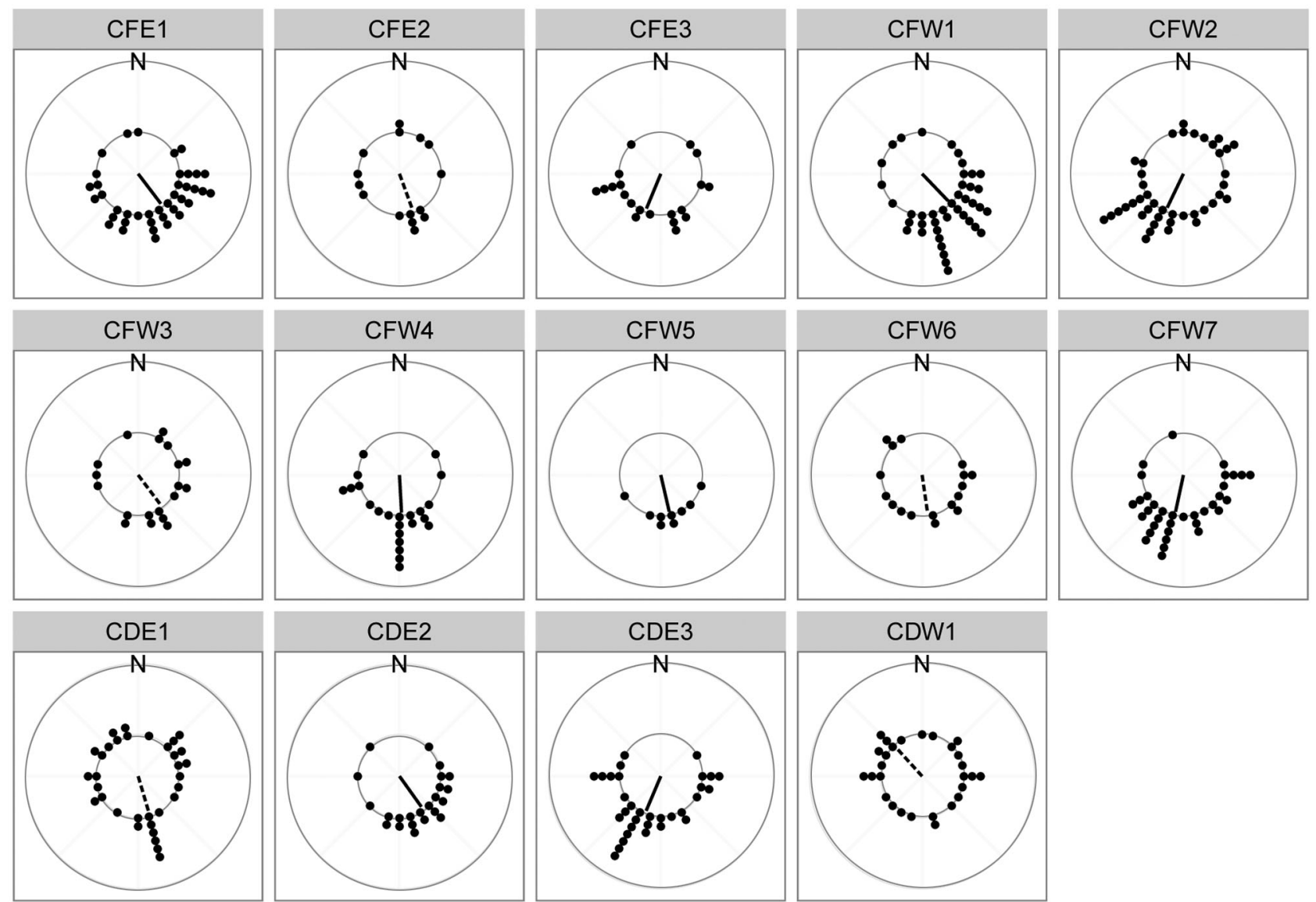

Fig. 2. Distribution of median bearings of directional runs of Chromis atripectoralis using Following and drifting in situ chamber (DISC) methodology. Points: mean bearings of directional runs; black radii: 2nd-order mean bearing (solid if $\mathrm{p}<0.05$, dashed if $\mathrm{p}>0.05)$. See Table 1 for statistics for each plot. The 4-symbol dataset codes indicate the species (C: C. atripectoralis), method (F: Following; D: DISC), area (E: East; W:West), and data-set number
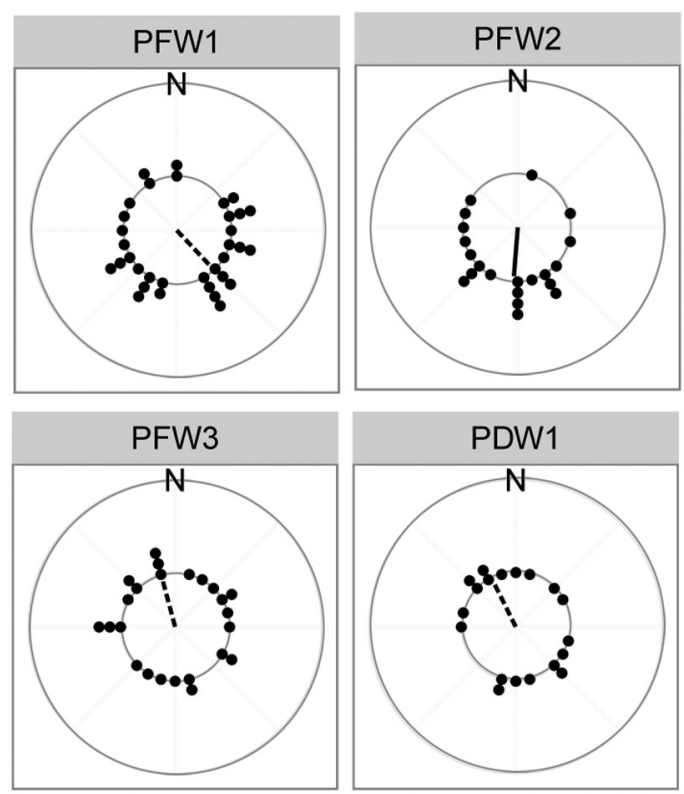

$(\mathbf{r}=0.76,0.87,0.85)$, there was no significant difference in within-run precision among the 5 time periods: $08: 30-10: 30,10: 30-12: 30,12: 30-14: 30,14: 30-$ $16: 30,16: 30-18: 02 \mathrm{~h}$ (KW test, $\mathrm{p}=0.20$ for sunny periods, and $p=0.48$ for all data). This provides weak support for the use of celestial cues in orientation.

All 33 larvae observed in sunny conditions when solar elevation (SoEv, i.e. the angle of the sun above the horizon) was less than $50^{\circ}$ had significant directionality. In contrast, 72 of 81 larvae observed when SoEv exceeded $50^{\circ}$ in sunny conditions had significant directionality. These 2 frequencies were significantly different $\left(\chi^{2}, \mathrm{p}=0.046\right)$. In sunny conditions, when SoEv was used to partition the data into 4 groups $\left(10-30^{\circ}, 30-50^{\circ}, 50-70^{\circ}, 70-90^{\circ}\right)$, median precision (r) was highest in the $10-30^{\circ}$ group $(0.928$,

Fig. 3. Distribution of median bearings of directional runs of Pomacentrus lepidogenys using Following and DISC methodology. ' $\mathrm{P}$ ' in dataset code: P. lepidogenys; all other details as in Fig. 2 


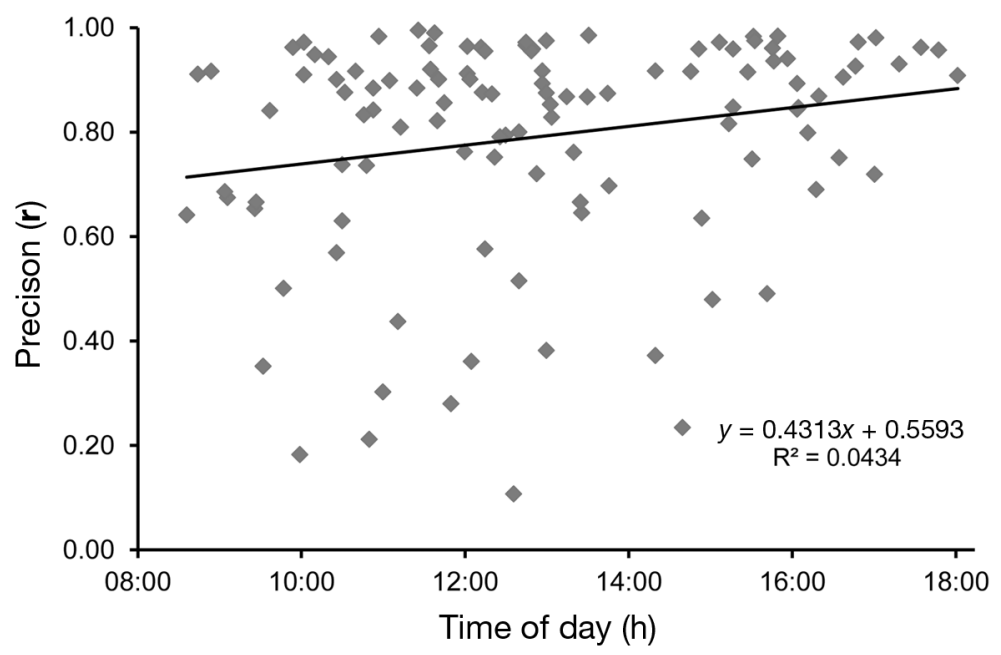

Fig. 4. Relationship between within-run $\mathbf{r}$ (i.e. directional precision), and time of day for Chromis atripectoralis on the west side of Lizard Island using Following methods under sunny conditions

$\mathrm{n}=8)$. However, there was not a significant correlation between SoEv and precision $(\mathbf{r}): \mathrm{R}^{2}=0.02, \mathrm{p}=$ 0.11 . Under sunny skies, there was not a significant difference in precision between the 4 SoEv groups $(\mathrm{p}=0.182, \mathrm{KW}$ test; Table 2$)$, which varied in median $\mathbf{r}$ from 0.85 to 0.86 , nor was there a significant difference when observations were pooled into 2 groups: $<50^{\circ}$ and $>50^{\circ}$ (MW test, $\mathrm{p}=0.42$ ). With one exception, similar results were obtained when all data were included ( $p=0.51$, KW test), although median $\mathbf{r}$ values were lower in all groups by about 0.02 . The exception was that when all data were included, the frequency of larvae with significant directionality did not differ between the $<50^{\circ}$ and $>50^{\circ}$ groups: 51 of 55 , and 87 of 99 , respectively $\left(\chi^{2}, p=0.34\right)$. The use of some sorts of celestial cues for orientation is thought to be easier when the sun is low in the sky, and these results provide limited support for that kind of use.

There was a significant, but weak correlation between time of day and within-run mean bearings during sunny periods $\left(\mathrm{CC}\right.$ correlation, $\mathrm{r}_{\mathrm{CC}}=0.057, \mathrm{p}<$ $0.05, \mathrm{n}=105$ ): bearings tended to be more easterly in the morning and more westerly in the mid to late afternoon. Unfortunately, CC correlation is difficult to portray in a 2-dimensional figure, especially when many values are involved (but see Fig. 5 for the relationship between among-run median bearing and time of day). Similar results were obtained when all data were included $\left(\mathrm{r}_{\mathrm{CC}}=0.086, \mathrm{p}<0.05, \mathrm{n}=138\right)$, but with a slightly higher correlation coefficient. This provides somewhat equivocal support for the use of celestial cues for orientation (see 'Discussion' for more detail).
When SoEv was used as the independent variable, rather than time of day, a non-significant negative correlation between SoEv and $\mathbf{r}$ was found. This was the case both when all data were used $\left(R^{2}=0.01, p=0.228, n=154\right)$, and when only observations taken under sunny skies were used $\left(\mathrm{R}^{2}=0.02, \mathrm{p}=0.114, \mathrm{n}=\right.$ 114). These results provide no support for the use of celestial cues.

\section{Among-run orientation}

Only data from the 138 directional runs were used in analyses of among-run orientation.

Among-run mean bearings were southerly overall, regardless of whether it was cloudy or sunny. When all data were included, median bearing was $166^{\circ}(\mathbf{r}=0.32, \mathrm{p}=0.65 \mathrm{E}$ 7 , $\mathrm{R}$ test, $\mathrm{n}=138$ ). Under sunny conditions, median bearing was $170^{\circ}(\mathbf{r}=0.35, \mathrm{p}=2.06 \mathrm{E}-6$, $\mathrm{R}$ test, $\mathrm{n}=105)$. Under cloudy skies, median bearing was $188^{\circ}$, although this was not significant $(\mathbf{r}=0.20, \mathrm{p}=0.395$, $\mathrm{R}$ test, $\mathrm{n}=24$ ). The distribution of mean bearings was not significantly different between sunny $(\mathrm{n}=105)$ and cloudy $(\mathrm{n}=24)$ conditions (WU2 test, $\mathrm{p}>0.5)$. This was not consistent with the use of celestial cues.

Orientation data for C. atripectoralis, when divided into five $2 \mathrm{~h}$ periods, revealed time-dependent changes in both precision and direction of orientation. When all data for directional individuals were used, significant orientation was found in all but 1 of the 5 time periods (Fig. 6, Table 2). The 14:3016:30 $\mathrm{h}$ period had a non-significant median bearing to the SE (Table 2). The mid-morning, late morning and early afternoon periods had significant orientation with median bearings between ESE and SSE (Table 2). In contrast, the late afternoon period had a significant mean bearing to SSW (Table 2), and its distribution of directions was significantly different from the other 4 periods ( $p<0.02$ to 0.001 , WU2 test), being more westerly and more precise $(\mathbf{r}=$ 0.67 vs. 0.14 to 0.48 ). In addition, the mid-afternoon period was significantly different from the late morning period ( $p<0.05$, WU2 test), being both less southerly and more variable ( $\mathbf{r}=0.16$ vs. 0.44 ). No other significant differences were found. These results are consistent with use of celestial cues for orientation.

When consideration was limited to the 105 sunny period runs, a similar, although less resolved picture 


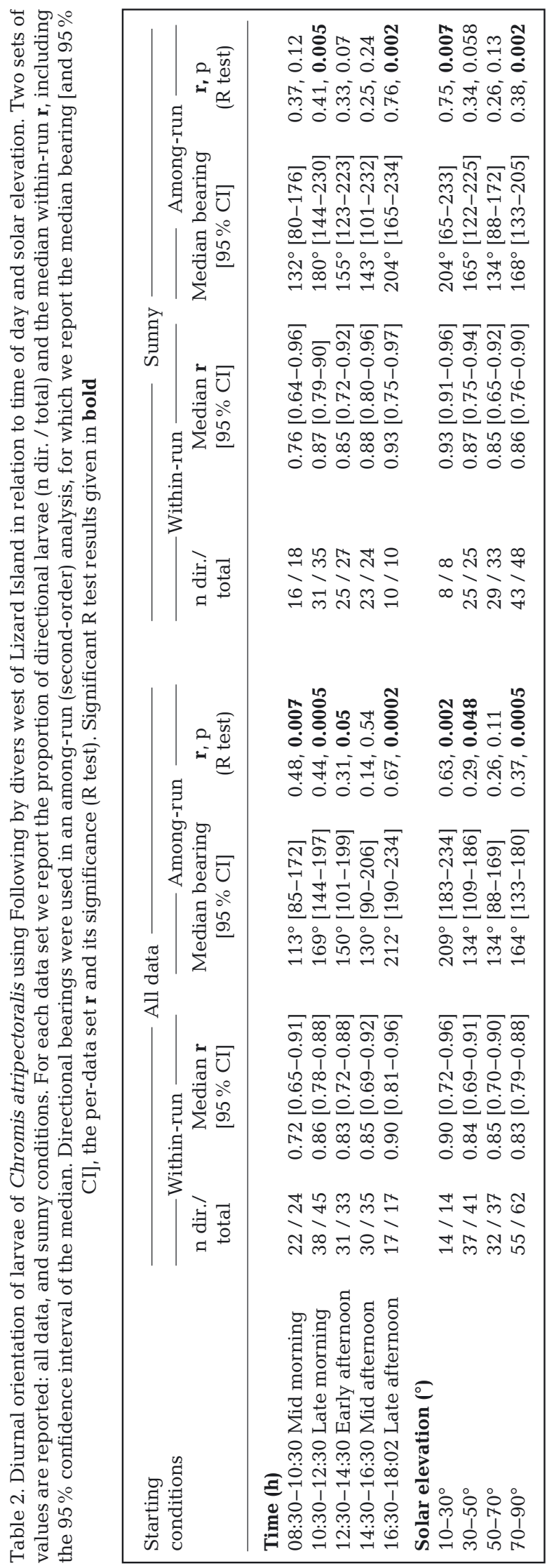

emerged (Table 2). Only 2 of the 5 periods (late morning and late afternoon) had significant orientation (Table 2). The late afternoon distribution of directions was significantly different $(p<0.02-0.05$, WU2 test) from the other 4 periods, being more westerly and more precise (Table 2). There were no other significant differences.

A significant relationship between time of day and median bearing emerged when among-run median bearings were calculated for each one-hour period between 08:00 and 18:00 h using all data from directional individuals. Fig. 5 depicts the among-run (second-order) median bearings for each of the $10 \times$ $1 \mathrm{~h}$ periods ( $\mathrm{n}$ ranged from 4 to 28 , total $=138$; Table 3). A linear regression fitted to these 10 mean values $\left(R^{2}=0.53, p=0.016\right)$ estimates an increase in mean bearing of roughly $10^{\circ}$ per hour from $110^{\circ}$ at 08:00-09:00 $\mathrm{h}$ to $203^{\circ}$ at 17:00-18:00 h (Fig. 5). These results are consistent with use of celestial cues for orientation.

There were too few observations under fully cloudy conditions for a full statistical analysis, but the 12 mid to late afternoon bearings were significantly different from the 12 morning to early afternoon bearings (WU2 test, $\mathrm{p}=0.0004$ ). The morning to early afternoon median bearing was $124^{\circ}(p=0.009, R$ test), whereas the mid to late afternoon median bearing was $271^{\circ}(p=0.17$, $R$ test), which is consistent with the patterns found during sunny periods. These results are consistent with use of celestial cues for orientation.

Bearings taken when SoEv was $<30^{\circ}$ were significantly different ( $p<0.01$, WU2 test) from those at higher SoEv values, being more westerly and more precise (Table 2) both with all data included, and under sunny skies. However, this was primarily because the 14 low SoEv values were all from late in the afternoon (16:30-18:02 h), when orientation was both more westerly and more precise than earlier in the day. At higher SoEv values $\left(30-50^{\circ}, 50-70^{\circ}\right.$ and $\left.70-90^{\circ}\right)$, median bearings were southerly $\left(134-164^{\circ}\right)$, and the distribution of bearings did not differ among the $3 \mathrm{SoEv}$ groupings that were $>30^{\circ}(\mathrm{p}>0.2$, WU2 test). These results are consistent with use of celestial cues for orientation.

\section{Following and DISC compared}

When DISC and Following were compared, differences in precision between methods were found, but differences in orientation between methods were no more likely than differences within methods. 


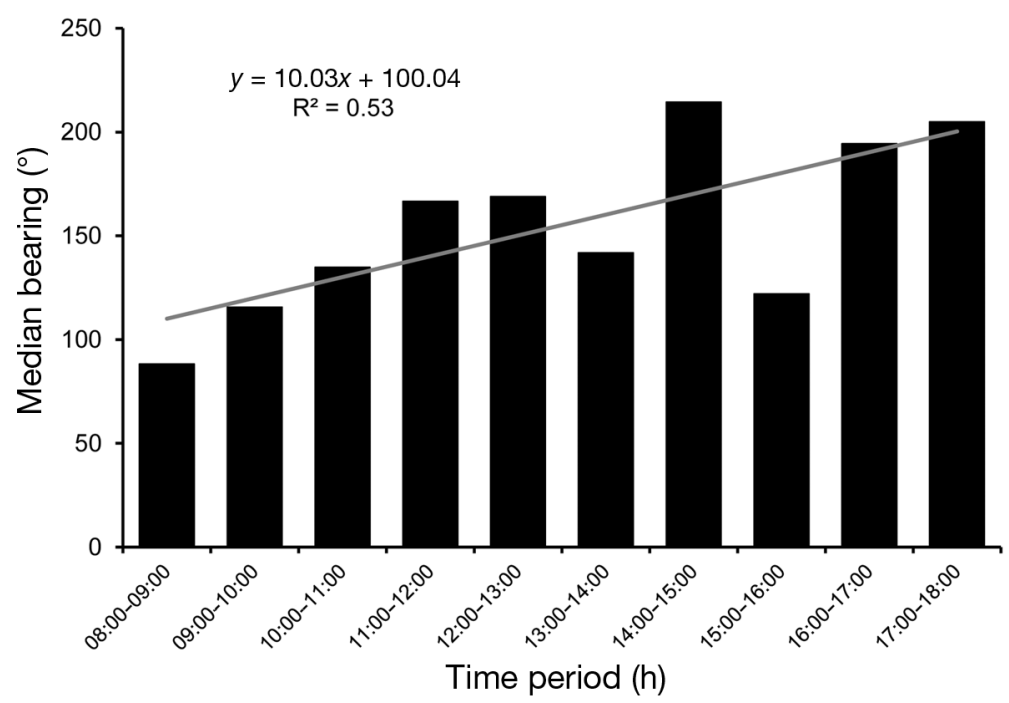

Fig. 5. Among-run (2nd order) median bearings of Chromis atripectoralis larvae as measured by Following on the west side of Lizard Island during one-hour time periods between 08:00 and 18:00 $\mathrm{h}$. The regression line has $\mathrm{p}=0.016$. Table 3 provides details of the median bearings

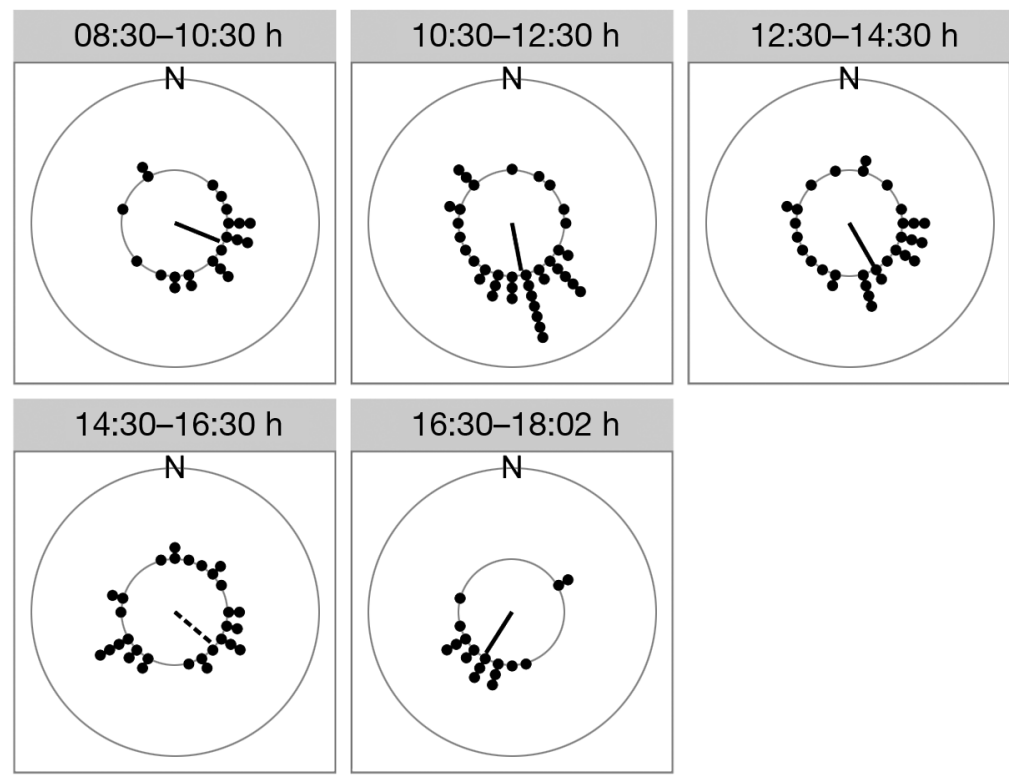

Fig. 6. Distribution of median bearings of directional Chromis atripectoralis during 5 diurnal periods on the west side of Lizard Island using Following methods. Details as in Fig. 2. See Table 2 for statistics of each plot

\section{Within-run precision}

Chromis atripectoralis (Table S1A in the Supplement). Among the 91 meaningful pairwise comparisons of within-run precision (r) among all data sets (MW test), there was not a significant difference in the proportion of significant differences between within-method (43.1\%) and cross-method comparisons $(57.5 \%)\left(\chi^{2}, p=0.25\right)$. However, pairwise MW tests within the 4 method-by-location categories revealed that precision was always significantly lower for DISC than for Following (MW, all $\mathrm{p}<10^{-5}$ ) regardless of location. Finally, when data were pooled by method, within-run precision was significantly lower for DISC (median $\mathbf{r}=0.64$ ) than for Following (median $\mathbf{r}=0.87$; Table 1; MW test, $\mathrm{p}<10^{-7}$ ).

Pomacentrus lepidogenys (Table S1B in the Supplement). Pairwise comparison of DISC within-run precision with the 3 Following data sets, revealed DISC median $\mathbf{r}$ (0.75) was significantly lower than Following PFW2 and PFW3 median $\mathbf{r}(0.84$, $0.89, p=0.03-0.04$ MW test), but not different from Following PFW1 $(0.79, \mathrm{p}=$ 0.65). Note that for the same month and location, precision was lower for DISC than Following (PFW3). In contrast, the only difference in median $\mathbf{r}$ among the 3 Following data sets was that PFW1 was significantly different from PFW2 (0.79 v. $0.89, \mathrm{p}=0.02)$. However, when all Following data were pooled (median $\mathbf{r}=0.77$ ) and compared to the DISC data (median $\mathbf{r}=0.69$ ), there was not a significant difference in precision between methods $(\mathrm{MW}, \mathrm{p}=0.095)$.

\section{Orientation}

Chromis atripectoralis (Table S2A in the Supplement). Of the 91 meaningful pairwise comparisons, 30 returned a significant difference in distribution of bearings (WU2 test, $\mathrm{p}<0.05$ ). Of the 40 crossmethod comparisons (DISC vs. Following), 15 were significant $(37.5 \%)$. Five of 6 (83\%) DISC vs. DISC comparisons were significant, whereas only 10 of 45 (22.2\%) Following vs. Following comparisons were significant. This difference in proportions for withinmethod comparisons is significant (Fisher's Exact test, $\mathrm{p}=0.006)$, implying that DISC data sets were less consistent in orientation than Following ones.

This implied method-dependent difference in orientation was primarily due to a single DISC data set, CDW1. Six of the 15 significant cross-method differ- 
Table 3. Median bearings of $C$. atripectoralis for $1 \mathrm{~h}$ time periods between 08:00 and 18:00 $\mathrm{h}$ west of Lizard Island

\begin{tabular}{|c|c|c|c|c|c|}
\hline \multirow{2}{*}{$\begin{array}{l}\text { Time period } \\
\text { (h) }\end{array}$} & \multirow[t]{2}{*}{$\mathrm{n}$} & \multicolumn{2}{|c|}{ — Bearing $\left({ }^{\circ}\right)-$} & \multirow{2}{*}{$\begin{array}{c}\mathrm{p} \\
\text { (R test) }\end{array}$} & \multirow[t]{2}{*}{$\mathbf{r}$} \\
\hline & & Median & $95 \%$ CI & & \\
\hline 08:00-09:00 & 5 & 88 & $57-176^{\mathrm{a}}$ & 0.045 & 0.764 \\
\hline 09:00-10:00 & 11 & 116 & 80-193 & 0.067 & 0.492 \\
\hline 10:00-11:00 & 16 & 135 & $39-172$ & 0.213 & 0.312 \\
\hline 11:00-12:00 & 14 & 167 & $123-192$ & 0.004 & 0.611 \\
\hline $12: 00-13: 00$ & 28 & 169 & $123-223$ & 0.120 & 0.275 \\
\hline $13: 00-14: 00$ & 16 & 142 & $87-199$ & 0.043 & 0.439 \\
\hline $14: 00-15: 00$ & 4 & 214 & $126-317^{a}$ & 0.938 & 0.134 \\
\hline $15: 00-16: 00$ & 19 & 122 & $43-232$ & 0.816 & 0.105 \\
\hline $16: 00-17: 00$ & 14 & 194 & $101-274$ & 0.209 & 0.336 \\
\hline 17:00-18:00 & 11 & 205 & $65-234$ & 0.013 & 0.609 \\
\hline
\end{tabular}

ences involved the CDW1 data set, which had a median bearing of $318^{\circ}\left(140-200^{\circ}\right.$ for other DISC sets, and $136-206^{\circ}$ for Following sets). The size of the difference in median bearing (median $55^{\circ}$ ) for the 11 significant within-Following comparisons was not significantly different from that of the 8 cross-method significant comparisons involving the $3 \mathrm{CDE}$ data sets (median $\left.56^{\circ}\right)(\mathrm{MW}$ test, $\mathrm{p}=0.91)$. In contrast, the 8 cross-method comparisons involving CDW1 had significantly larger differences in median bearing $\left(\right.$ median $\left.=122^{\circ}\right)$ than did the 11 within-Following comparisons (MW test, $\mathrm{p}=0.0003$ ).

For $C$. atripectoralis there was no meaningful difference between methods in variability in among-run orientation (Table S2A in the Supplement). None of the pairwise contrasts between data sets revealed a significant difference in angular dispersion ( $\mathrm{W}$ test). When the comparison was based on data grouped by method and location (4 groups, based on DISC, Following, East and West), no significant difference in angular dispersion was found ( $\mathrm{W}$ test, $\mathrm{p}=0.21$ ). When only the 2008 data sets (4 each DISC and Following) were included, a significant difference was found ( $\mathrm{W}$ test, $\mathrm{p}=0.007$ ), but it was entirely due to the contrast between the most and least variable datasets (CDE1 and CFE5, respectively). The other data sets did not differ significantly in angular dispersion from each other or from either the most variable or the least variable sets. Therefore, for C. atripectoralis, variability in among-run orientation does not appear to differ between DISC and Following.

Pomacentrus lepidogenys (Table S2B in the Supplement). Only one of the $P$. lepidogenys data sets, PFW2, had a significant among-run mean orientation (Table 1). There were significant differences in distribution of bearings among data sets collected at different times, but no differences were found between data sets collected at the same time (all based on WU2). Thus, the distribution of bearings of the DISC data (median bearing of $334^{\circ}$, all taken in 2008) was not significantly different from that of the 2008 Following data (median direction $346^{\circ}$ ), nor did morning Following data (PFW1, median bearing $151^{\circ}$ ) differ from afternoon Following data (PFW2, median bearing $185^{\circ}$ ). So, the key cross-method comparison did not detect any difference in distribution of bearings between DISC and Following data. In contrast, all 4 comparisons involving data collected at different times returned significant differences in distribution of bearings. It seems that orientation of P. lepidogenys larvae varies on a temporal basis, but that both methods give similar estimates at any one time.

There was no difference in angular dispersion among the $4 P$. lepidogenys data sets $(\mathrm{p}=0.10-0.71$, W tests; Table S2B in the Supplement) or between DISC data (PDW1) and Following data (PFW3) from the same time period ( $\mathrm{p}>0.20, \mathrm{~W}$ test). Therefore, for $P$. lepidogenys, variability of among-run orientation does not appear to differ between DISC and Following.

\section{DISCUSSION}

Settlement-stage larvae of both study species have mean swimming speeds greater than mean current speeds in the study region, so both have the ability to greatly influence their dispersal given sufficient orientation abilities. The 8-10 mm larvae of Chromis atripectoralis have average in situ swimming speeds of 22-25 $\mathrm{cm} \mathrm{s}^{-1}$, whereas the larger (11-13 mm) larvae of Pomacentrus lepidogenys are slower at 15$17 \mathrm{~cm} \mathrm{~s}^{-1}$ (Leis \& Carson-Ewart 2003). In comparison, average current speeds in the Lizard Island region are 11-17 $\mathrm{cm} \mathrm{s}^{-1}$, depending on location (Frith et al. 1986, Leis \& Carson-Ewart 2003). The large majority $(89.0-93.5 \%)$ of individuals of both study species swam in a significantly directional manner, regardless of the method of observation, location or time.

\section{Orientation variability among locations and years}

Larvae of C. atripectoralis had very consistent orientation within runs, among runs within data sets, among data sets, among years, among distances from the reef edge and between sides of the island. All Following data sets collected over $10 \mathrm{yr}$ and involving over 300 larvae and 3 of 4 DISC data sets had a 
median bearing to the south: $136-206^{\circ}$ for Following and $144-203^{\circ}$ for DISC. Further, in 7 of 10 Following and 2 of 4 DISC data sets, the southerly median bearings were significantly directional. Virtually identical median bearings were found on both sides of Lizard Island, and swimming direction was southerly at all distances from shore. Two of the 3 Following data sets without significant orientation were from experiments when underwater broadcasts of nocturnal reef sound were thought to have disrupted the normal orientation of the larvae (Leis et al. 2002).

In fact, some significant differences in median direction between data sets could be identified, but these were relatively small differences within the general envelope of southerly swimming. The sole exception was the DISC data set from west of the island (CDW1), which had non-significant northwest orientation. This DISC dataset was obtained during the same period (Nov-Dec 2008) when CFW6, the only non-significant Following data set not manipulated by sound, was obtained. The distribution of bearings in the these Nov/Dec 2008 Following and DISC data sets were not significantly different.

At present, it is unknown whether location independence in orientation of C. atripectoralis larvae extends beyond the Lizard Island region to other locations. The species has a wide range, extending from the western Indian Ocean to the Central Pacific, but behaviour of its larvae has not been studied elsewhere. Regardless, the location-independent orientation of this species in the vicinity of Lizard Island has implications for the cues used to achieve it. Location independence of orientation implies use of location-independent cues such as celestial or magnetic cues (Leis et al. 2011). In larval marine fishes, there is some evidence for use of celestial cues in 2 families that inhabit tropical reefs, Pomacentridae and Apogonidae (Leis \& Carson-Ewart 2003, Mouritsen et al. 2013), but none for use of magnetic cues. If orientation is location-independent, modelling larval dispersal will be more straightforward than if orientation changes with time or location (Staaterman et al. 2012, Staaterman \& Paris 2013).

The reasons for the consistent southerly orientation of C. atripectoralis larvae (and apparently, larvae of other pomacentrids; Leis et al. 2007), regardless of location or time, are not clear. In an earlier study, using a subset of the data summarized here, involvement of solar cues was suggested (Leis \& CarsonEwart 2003). This suggestion has received some support from Mouritsen et al. (2013) and the diurnal portions of the present study, but this only addresses the proximate means by which orientation might be accomplished, not why larvae might prefer to swim to the south near Lizard Island during the day. In the Lizard Island region, the most common current direction is from south to north (Frith et al. 1986, Leis \& Carson-Ewart 2003, Choukroun et al. 2010). All else being equal, larvae that swim primarily to the south in the Lizard Island region, would, on average, remain closer to their natal reef than larvae that did otherwise, resulting in limited dispersal (Leis et al. 2007), which has clear advantages. We do not suggest that the larvae directly detect the current and swim into it. Indeed, the available evidence is that larvae have the same swimming direction regardless of the current at any particular time (Leis \& CarsonEwart 2003). It is more likely is that a 'regional swimming direction' has evolved to counteract the prevailing non-tidal current. Alternatively, individuals without a southerly swimming orientation would be advected from Lizard Island by the prevailing current because it would not be counteracted by swimming. But, if the latter alternative were the case, one would expect larvae which did not swim to the south to be advected into the Lizard Island region from the south, resulting in a range of swimming directions near Lizard Island.

In contrast, orientation behaviour of Pomacentrus lepidogenys larvae was less precise among runs, and seemed to change over time as well as with distance from shore. Two of 3 P. lepidogenys Following data sets had a median bearing to the south, but only the late afternoon data set had significant orientation, again to the south. One Following and the sole DISC $P$. lepidogenys data set had non-significant median bearings to the north. Clearly, the 2 species have different orientation behaviour.

\section{Diurnal variation in orientation}

The diurnal changes in C. atripectoralis orientation precision found here are consistent with the use of a celestial orientation cue or cues, as is the lower within-run precision under cloudy conditions, but there were some inconsistencies. Within-run precision was weakly positively correlated with time of day, increasing from mid-morning to late afternoon, but there were no significant differences in precision among the 5 diurnal time periods. Similar results were obtained when solar elevation (SoEv) was used to partition the data, rather than time, except that during sunny periods there was a higher proportion of significantly orientated individuals when the sun angle was low $\left(<50^{\circ}\right)$ than when it was high. If celes- 
tial cues were being used by larval $C$. atripectoralis for orientation, precision would be expected to be lowest in the middle of the day (high SoEv), and higher in early morning and late afternoon when SoEv was low. In other words, one should expect a negative correlation between SoEv and precision, but no correlation between time of day and precision. In contrast, we found a significant, weak positive correlation with time of day, and a non-significant negative correlation with SoEv. One possible explanation for this is that we had no observations earlier than 08:30 $\mathrm{h}$ (when SoEv would have been about $40^{\circ}$ ). In contrast, we had 20 observations after 16:00 h, when SoEv would have been $<40^{\circ}$ ). In large part this was due to the fact that the $360 \mathrm{~m}$ high peak of Lizard Island to the east blocks direct view of the sun in the early morning from much of the western (leeward) study area. Thus, the weak correlation between precision and time of day (between 08:30 and 18:00 h) is perhaps not unexpected if precision is highest at low SoEv. However, the lack of a significant correlation between precision and SoEv is not consistent with use of celestial cues. Based on the results presented here, there is, at best, only a weak connection between time of day (and SoEv) and orientation precision.

The change in direction of C. atripectoralis orientation from SE in mid-morning to SW in late afternoon is consistent with use of celestial cues for orientation. This is reflected in a significant, but weak, correlation between within-run mean bearing and time of day, and a significant difference in the distribution of bearings between the late afternoon period and the earlier periods. The increase in median bearing of about $10^{\circ}$ per hour from 08:00 to $18: 00 \mathrm{~h}$ is also consistent with use of a celestial cue.

There were too few observations on $P$. lepidogenys for a full examination of diurnal variation in orientation, but previous observations west of Lizard Island showed differences in orientation between morning and late afternoon that are consistent with use of celestial cues (Leis \& Carson-Ewart 2003). Withinrun precision during mid-morning to early afternoon (09:00-13:40 h, mean $\mathbf{r}=0.72$ ) was lower than during mid to late afternoon (15:00-17:00 $\mathrm{h}$, mean $\mathbf{r}=0.82)$, although the difference was of marginal significance ( $p=0.055$; Leis \& Carson-Ewart 2003). Further, it was only during the afternoon period that among-run orientation in P. lepidogenys was significantly directional (Leis \& Carson-Ewart 2003), and the late afternoon mean bearing was more westerly than the morning mean bearing. In the late afternoon $P$. lepidogenys larvae also had a shallower vertical distribu- tion than they did in the morning, and this was also true for C. atripectoralis at 100 and $1000 \mathrm{~m}$ from shore (but not at $500 \mathrm{~m}$; Leis 2004). In contrast, vertical distribution of $C$. atripectoralis did not differ significantly between cloudy and sunny periods (Leis 2004, unpubl. data), which might have been expected if larvae ascended in cloudy conditions to more readily detect downwelling, polarized light. If pomacentrid larvae use celestial cues for orientation, the underwater polarized light field would provide a stronger signal when the sun was lower in the sky in the late afternoon and it would be more readily detected at shallower depths (Novales Flamarique \& Hawryshyn 1997).

The results presented here are largely consistent with the use of celestial cues for orientation by C. atripectoralis larvae, and to a lesser extent by $P$. lepidogenys larvae. Diver following observations are not likely to lead to more definitive conclusions. Manipulative field and laboratory experiments, including use of DISC methodology, will be necessary.

If larval fishes use celestial cues for orientation as implied by our results, there are several interesting implications. (1) Celestial cues allow orientation over large spatial scales (Waterman 1988) and without regard to distance from particular sources of cues, such as scents or sounds emanating from coral reefs. (2) One would expect that orientation would be adversely affected by cloud cover because clouds obscure some or all of the celestial cue. The fact that within-run precision in C. atripectoralis was lower under cloudy conditions than sunny conditions is consistent with this expectation. However, importantly, orientation abilities did not disappear under cloudy conditions. The sun position is discernible through cloud cover in many situations, and the skylight polarization pattern under heavy cloud, although reduced, is not qualitatively different from that under clear skies (Hegedüs et al. 2007). Therefore, orientation using celestial cues in cloudy conditions may still be possible, albeit more difficult. Many tropical areas have distinct rainy or monsoon seasons, and the increased cloud cover associated with these seasons could result in poorer orientation, and perhaps ultimately, poorer settlement, on a seasonal basis. (3) Wind causes surface waves and these alter the underwater light field in several ways (e.g. Stramska \& Dickey 1998, Stramski \& Tegowski 2001, Hieronymi \& Macke 2012) including focusing/defocusing by waves, reflectance by bubbles caused by breaking waves, turbulence, and altered surface reflectivity. Potentially, these light field alterations could interfere with the ability of larval fishes to 
detect celestial cues, causing difficulties for orientation when winds are high. (4) Certain anthropogenic activities such as eutrophication, increased turbidity due to run-off or dredging, or pollution such as oil spills can decrease the strength and visibility of celestial cues when viewed from underwater. These would also be likely to decrease orientation precision. (5) Celestial cues should be strongest, and therefore easiest to use, in the upper portions of the water column, so one would expect animals that utilize celestial cues for orientation would be shallowliving, as are the larvae of the 2 pomacentrid species studied here (Leis 1991, 2004).

\section{Following compared to DISC}

Following and DISC methods provided very similar orientation results for the 2 study species. In both methods, the large majority of individual runs were directional. Within-run precision was somewhat greater in Following data sets. However, this might be due to the somewhat different way that orientation is measured by the 2 methods, and the tendency of larvae in the DISC to move back and forth along the perimeter of the observation arena when their swimming trajectory is blocked. Between-method differences in median direction were found, but similar differences were found in within-method contrasts.

Aside from one DISC C. atripectoralis data set from west of Lizard Island, the magnitude of the crossmethod differences in median bearings was nearly identical to that of within-Following differences. We can identify no obvious reason why the orientations estimated in that single DISC data set were so different from most of the Following data and the other DISC data. It was, however, the only C. atripectoralis DISC data set from west of Lizard Island, which is shallower than the east side of the island, and that may have influenced the results. We maintained the same DISC depth on both sides of the island for consistency, but C. atripectoralis larvae prefer somewhat shallower depths west of Lizard Island than off the east side (Leis 2004), although how this might influence horizontal orientation is not clear. It is also noteworthy that the Following data set from the same location during the same 2008 field trip was the only Following data set not manipulated by underwater sound broadcasts that did not have significant orientation to the south, and that its distribution of bearings was not significantly different from the DISC data set in question. In contrast, for P. lepidogenys,
DISC and Following results from west of the island during the same 2008 field trip were nearly identical (non-significant, median orientation to NW).

SCUBA divers are very noisy (Radford et al. 2005), so it is noteworthy that the Following method, which includes the noise of the divers and the attendant support boat, provided results similar to those of the DISC, which involve neither diver nor boat noise. In contrast, the broadcasting of reef sounds - but not 'white noise' - during Following experiments did influence orientation of larvae (Leis et al. 2002). These observations firstly alleviate potential concerns that the noise associated with Following might result in misleading orientation data, and secondly, demonstrate that $C$. atripectoralis larvae can distinguish among different sounds even when other potentially masking sounds are present.

Thus, it seems that Following and DISC can both be used to study orientation of larval fishes in the ocean, and will provide similar results. In many ways the 2 methods are complementary, and use of both can increase confidence in the resulting data. Alternatively, if differences in orientation between the 2 methods are found, this would highlight the need for caution, and perhaps lead to better understanding of just what determines orientation. Each approach has strengths and weaknesses. For example, swimming speed and depth selection are readily studied by Following, but would be difficult to study with DISC. In contrast, DISC can be used at any depth, both day and night (with an infrared camera), and over long periods, which Following cannot. The lack of information on what larvae do at night is perhaps the largest gap in knowledge of larval behaviour, and DISC offers interesting possibilities in this area. Perhaps most important, DISC can be used to manipulate sensory cues to help delineate the sensory basis of orientation in ways that Following cannot. For example, a filter or opaque shade over the DISC can be used to study how altering the underwater light field affects orientation (e.g. Berenshtein et al. 2014). It is only through such experimental manipulations in the ocean that the implications of observations like those from the present study, suggesting that fish larvae use celestial cues for orientation, can be tested.

Acknowledgements. This research was supported by a Hermon Slade Foundation grant to J.M.L. and C.B.P. and an ARC Discovery grant DP110100695 to J.M.L., U.E.S. and C.B.P. DISC development was funded in part by the Paris Lab and by NSF-OTIC 1155698 to C.B.P. We acknowledge the staff of Lizard Island Station for all sorts of things; the JCU light trap crew for sharing catches of larvae; and various people for help in the field, especially C. Wen and K. 
Fritsches. We also thank S. Bullock for editorial assistance. Research in 2008 was conducted under research permit G07/23614.1 from the Great Barrier Reef Marine Park Authority, and Australian Museum Animal Care and Ethics Committee Approval 07-02. Research in 2011 was carried out under GBRMPA research permit G34430.1 and University of Queensland Ethics Permit SBMS/276/11/ARC. See cited publications for information on permits for earlier observations.

\section{LITERATURE CITED}

Bay LK, Buechler K, Gagliano M, Caley MJ (2006) Intraspecific variation in the pelagic larval duration of tropical reef fishes. J Fish Biol 68:1206-1214

Berenshtein I, Kiflawi M, Shashar N, Wieler U, Agiv H, Paris CB (2014) Polarized light sensitivity and orientation in coral reef fish post-larvae. PLoS ONE 9:e88468

> Choukroun S, Ridd PV, Brinkman R, McKinna LIW (2010) On the surface circulation in the western Coral Sea and residence times in the Great Barrier Reef. J Geophys Res 115:C06013, doi:10.1029/2009JC005761

Fisher R, Leis JM (2009) Swimming performance in larval fishes: from escaping predators to the potential for long distance migration. In: Domenici P, Kapoor BG (eds) Fish locomotion: an etho-ecological approach. Science Publishers, Enfield, NH, p 333-373

Frith CA, Leis JM, Goldman B (1986) Currents in the Lizard Island region of the Great Barrier Reef Lagoon and their relevance to potential movements of larvae. Coral Reefs 5:81-92

Gould JL, Gould CG (2012) Nature's compass: the mystery of animal navigation. Princeton University Press, Princeton, NJ

> Hegedüs R, Åkesson S, Horváth G (2007) Polarization patterns of thick clouds: overcast skies have distribution of the angle of polarization similar to that of clear skies. J Opt Soc Am A Opt Image Sci Vis 24: 2347-2356

> Hieronymi M, Macke A (2012) On the influence of wind and waves on underwater irradiance fulctuations. Ocean Sci 8:455-471

Hindell JS, Jenkins GP, Moran SM, Keough MJ (2003) Swimming ability and behaviour of post-larvae of a temperate marine fish re-entrained in the pelagic environment. Oecologia 135:158-166

> Irisson JO, Guigand C, Paris CB (2009) Detection and quantification of marine larvae orientation in the pelagic environment. Limnol Oceanogr Methods 7:664-672

- Leis JM (1991) Vertical distribution of fish larvae in the Great Barrier Reef Lagoon, Australia. Mar Biol 109: $157-166$

Leis JM (2004) Vertical distribution behaviour and its spatial variation in late-stage larvae of coral-reef fishes during the day. Mar Freshw Behav Physiol 37:65-88

Leis JM (2010) Ontogeny of behaviour in larvae of marine demersal fishes. Ichthyol Res 57:325-342

Leis JM, Carson-Ewart BM (1997) In situ swimming speeds of the late pelagic larvae of some Indo-Pacific coral-reef fishes. Mar Ecol Prog Ser 159:165-174

Leis JM, Carson-Ewart BM (1998) Complex behaviour by coral-reef fish larvae in open-water and near-reef pelagic environments. Environ Biol Fishes 53: 259-266
Leis JM, Carson-Ewart BM (2003) Orientation of pelagic larvae of coral-reef fishes in the ocean. Mar Ecol Prog Ser 252:239-253

Leis JM, Sweatman HPA, Reader SE (1996) What the pelagic stages of coral reef fishes are doing out in blue water: daytime field observations of larval behaviour. Mar Freshw Res 47:401-411

Leis JM, Carson-Ewart BM, Cato DH (2002) Sound detection in situ by the larvae of a coral-reef damselfish (Pomacentridae). Mar Ecol Prog Ser 232:259-268

Leis JM, Hay AC, Clark DA, Chen IS, Shao KT (2006) Behavioral ontogeny in larvae and early juveniles of the giant trevally, Caranx ignobilis (Pisces: Carangidae). Fish Bull US 104:401-414

Leis JM, Wright KJ, Johnson RN (2007) Behaviour that influences dispersal and connectivity in the small, young larvae of a reef fish. Mar Biol 153:103-117

Leis JM, Hay AC, Howarth GJ (2009) Ontogeny of in situ behaviours relevant to dispersal and connectivity in larvae of coral-reef fishes. Mar Ecol Prog Ser 379: 163-179

> Leis JM, Siebeck UE, Dixson DL (2011) How Nemo finds home: the neuroecology of dispersal and of population connectivity in larvae of marine fishes. Integr Comp Biol 51:826-843

Mouritsen H, Atema J, Kingsford MJ, Gerlach G (2013) Sun compass orientation helps coral reef fish larvae return to their natal reef. PLoS ONE 8:e66039

North E, Gallego A, Petitgas P (2009) Manual of recommended practices for modelling physical-biological interactions in fish early life. Int Counc Expl Sea Coop Res Rep 295:1-112

Novales Flamarique I, Hawryshyn CW (1997) Is the use of underwater polarized light by fish restricted to crepuscular time periods? Vision Res 37:975-989

Paris CB, Guigand C, Irisson JO, Fisher R, D'Alessandro E (2008) Orientation With No Frame of Reference (OWNFOR): a novel system to observe and quantify orientation in reef fish larvae. In: Grober-Dunsmore R, Keller BD (eds) Proceedings of a Special Symposium, 9-11 November 2006, 59th Annual Meeting of the Gulf and Caribbean Fisheries Institute. US Department of Commerce, National Oceanic and Atmospheric Administration, Office of National Marine Sanctuaries, Belize City, Belize, p 52-62

Paris CB, Atema J, Irisson JO, Kingsford MJ, Gerlach G, Guigand CM (2013) Reef odor: a wake up call for navigation in reef fish larvae. PLoS ONE 8:e728081

Pomozi I, Horvath G, Wehner R (2001) How the clear-sky angle of polarization pattern continues underneath clouds: full-sky measurements and implications for animal orientation. J Exp Biol 204:2933-2942

> Radford CA, Jeffs AG, Tindle CT, Cole RG, Montgomery JC (2005) Bubbled waters: the noise generated by underwater breathing apparatus. Mar Freshw Behav Physiol 38:259-267

Staaterman E, Paris CB (2013) Modelling larval fish navigation: the way forward. ICES J Mar Sci doi:10.1093/ icesjms/fst103

Staaterman E, Paris CB, Helgers J (2012) Orientation behavior in fish larvae: a missing piece to Hjort's critical period hypothesis. J Theor Biol 304:188-196

Stobutzki IC, Bellwood DR (1998) Nocturnal orientation to reefs by late pelagic stage coral reef fishes. Coral Reefs 17:103-110 
Stramska M, Dickey TD (1998) Short-term variability of the underwater light field in the oligotrophic ocean in response to surface waves and clouds. Deep-Sea Res I 45:1393-1410

Stramski D, Tegowski J (2001) Effects of intermittent entrainment of air bubbles by breaking wind waves on ocean reflectance and underwater light field. J Geophys Res 106:31345-31360

Trnski T (2002) Behaviour of settlement-stage larvae of fishes with an estuarine juvenile phase: in situ observations in a warm-temperate estuary. Mar Ecol Prog Ser

Editorial responsibility: Nicholas Tolimieri, Seattle, Washington, USA
242:205-214

Waterman TH (1988) Polarization of marine light fields and animal orientation. In: Blizard MA (ed) Proc Soc PhotoOptical Instrumentation Engineers (SPIE), Vol 925. Ocean Optics IX, 4 Apr 1988, Orlando, FL. SPIE, Bellingham, WA, p 431-437

Wellington GM, Victor BC (1989) Planktonic larval duration of one hundred species of Pacific and Atlantic damselfishes (Pomacentridae). Mar Biol 101:557-567

Zar JH (1996) Biostatistical analysis, 3rd ed. Prentice Hall, Upper Saddle River, NJ

Submitted: November 25, 2013; Accepted: March 19, 2014 Proofs received from author(s): May 19, 2014 